\title{
Type II endoleaks: challenges and solutions
}

\author{
This article was published in the following Dove Press journal: \\ Vascular Health and Risk Management \\ 2 March 2016 \\ Number of times this article has been viewed
}

\section{Andrew Brown' \\ Greta K Saggu' \\ Matthew J Bown ${ }^{2}$ \\ Robert D Sayers ${ }^{2}$ \\ David A Sidloff',2 \\ 'Department of Vascular Surgery, Queens Medical Centre, University of Nottingham, Nottingham, \\ ${ }^{2}$ Department of Cardiovascular Sciences, National Institute for Health Research Leicester Cardiovascular Biomedical Research Unit, University of Leicester, Leicester, UK}

Correspondence: David A Sidloff

Department of Cardiovascular Sciences, Level 2, RKCSB, Leicester Royal Infirmary, Infirmary Square, Leicester, LE2 7LX, UK

Tel +447736833606

Email ds343@le.ac.uk
Abstract: Type II endoleaks are the most common endovascular complications of endovascular abdominal aortic aneurysm repair (EVAR); however, there has been a divided opinion regarding their significance in EVAR. Some advocate a conservative approach unless there is clear evidence of sac expansion, while others maintain early intervention is best to prevent adverse late outcomes such as rupture. There is a lack of level-one evidence in this challenging group of patients, and due to a low event rate of complications, large numbers of patients would be required in well-designed trials to fully understand the natural history of type II endoleak. This review will discuss the imaging, management, and outcome of patients with isolated type II endoleaks following infra-renal EVAR.

Keywords: aorta, endovascular, endograft, endoleak, embolization

\section{Introduction}

Endovascular abdominal aortic aneurysm repair (EVAR) has over time become the preferred approach to treating abdominal aortic aneurysms (AAA) when anatomically suitable. One reason for this is that EVAR utilizes a minimally invasive approach that has been associated with reduced perioperative mortality, morbidity, and length of hospital stay. ${ }^{1,2}$ However, these initial benefits appear to be reduced over time. For example, recent studies have demonstrated increases in reintervention rates post-EVAR and a convergence of mortality rates after 4 years..$^{3-6}$ One explanation for this convergence may be an increase in late aneurysm rupture. . $^{3,5,6}$

The most common indication for reintervention post-EVAR is the treatment of endoleak (Table 1), ${ }^{7}$ defined as continued perfusion of the aneurysm sac despite endograft deployment. ${ }^{7}$ Type II endoleaks (Figure 1) are the most common, occurring in $10 \%-44 \%$ of patients and comprising approximately half of all endoleaks. ${ }^{8,9}$ Type II endoleak arises secondary to backflow from collateral arteries, most notably the inferior mesenteric and lumbar vasculature; however, they may arise from other aortic collaterals such as the median sacral artery or accessory renal arteries. ${ }^{10}$ Endoleaks with a "simple" inflow and outflow vessel may behave differently to "complex" type II endoleaks with a nidus of involved vessels. These complex leaks are hypothesized to behave like arterial-venous malformations, recruiting vessels over time, and may therefore be more difficult to embolize. ${ }^{10}$

These can be subdivided (Table 2) into early (occurring within 30 days of EVAR), persistent (those lasting longer than 6 months), or late (those occurring after 1 year) leaks. The significance of type II endoleaks has divided opinion, with some advocating 


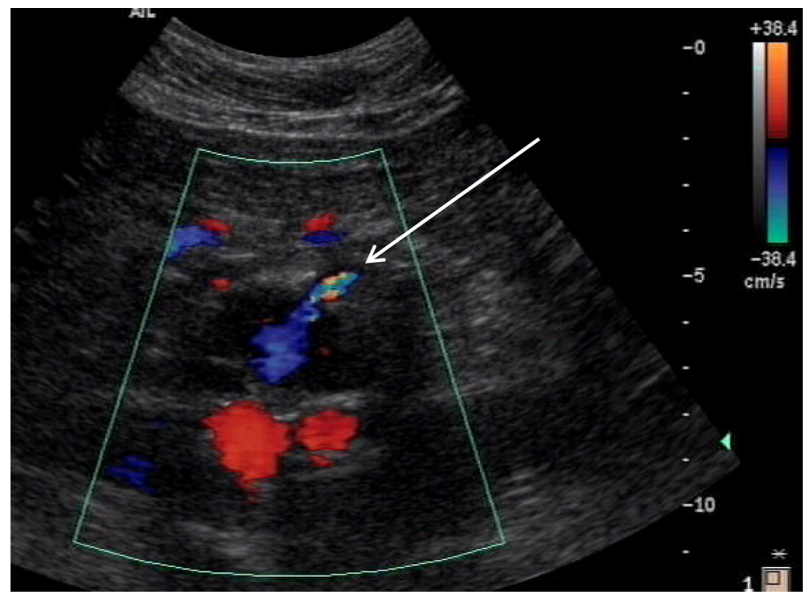

Figure I Duplex image showing type II endoleak entering aneurysm sac post-EVAR (arrow).

Abbreviation: EVAR, endovascular abdominal aortic aneurysm repair.

a conservative approach, ${ }^{7}$ while others maintain early intervention is best to prevent adverse late outcomes such as sac expansion and rupture. ${ }^{10-12}$ This review will discuss the imaging, management, and outcome in patients with isolated type II endoleaks following EVAR.

\section{Imaging of type II endoleak}

The European Society for Vascular Surgery recommends that within 30 days of EVAR, a baseline computed tomography angiogram (CTA) and plain radiograph should be performed. ${ }^{13}$ Following this, if no endoleak or component complication is identified, repeat imaging should be performed approximately every 12 months to identify the development of any complications and prevent rupture.

Plain radiographs are utilized during serial follow-up and are accurate in assessing stent malfunction, for example, migration, fracture, or disconnection. However, they provide

Table I Classification of endoleaks

\begin{tabular}{|c|c|}
\hline Type of endoleak & Definition \\
\hline Type I endoleak & $\begin{array}{l}\text { Failure to create an adequate } \\
\text { circumferential seal } \\
\text { - la - proximal attachment site } \\
\text { - lb - distal attachment site } \\
\text { - Ic - common iliac artery }\end{array}$ \\
\hline Type II endoleak & $\begin{array}{l}\text { Backflow of blood from aortic collaterals } \\
\text { into the aneurysmal sac }\end{array}$ \\
\hline Type III endoleak & $\begin{array}{l}\text { Endoleak secondary to structural failure of } \\
\text { endograft } \\
\text { - Illa - component disconnection } \\
\text { - IIlb - stent fabric disturbance }\end{array}$ \\
\hline Type IV endoleak & Related to graft fabric porosity \\
\hline $\begin{array}{l}\text { Type V endoleak } \\
\text { (endotension) }\end{array}$ & $\begin{array}{l}\text { Continued high intrasac pressure following } \\
\text { EVAR without evidence of continued } \\
\text { aneurysm sac perfusion }\end{array}$ \\
\hline
\end{tabular}

Abbreviation: EVAR, endovascular abdominal aortic aneurysm repair.
Table 2 Classification of type II endoleak

\begin{tabular}{ll}
\hline Type II endoleak classification \\
\hline Early & Occurring within 30 days of EVAR \\
Late & Occurring after I year of EVAR \\
Persistent & Present for more than 6 months after EVAR \\
\hline
\end{tabular}

Abbreviation: EVAR, endovascular abdominal aortic aneurysm repair.

no reliable measurement of aneurysm sac size or expansion. ${ }^{13}$ Duplex ultrasound (DUSS) is readily accessible and has several advantages in comparison to CTA (Figure 2), which include no risk of exposure to ionizing radiations or risk of contrast-induced nephropathy. However, DUSS has a lower sensitivity and specificity for endoleak when compared to CTA. ${ }^{14,15}$ Detection of type II endoleaks can be challenging; low-flow leaks may be missed completely, and overlap between different endoleaks can make classification difficult. ${ }^{16}$ Practical limiting factors such as body habitus and intervening bowel gas patterns also make the assessment of the aneurysm sac/neck difficult. Despite these limitations, DUSS is thought to be a satisfactory technique in detecting endoleak requiring intervention. ${ }^{17}$

One approach to improving the sensitivity of DUSS in diagnosing endoleak is to use contrast-enhanced ultrasound (CEUS), which has been shown to demonstrate detection rates similar to those exhibited by CTA..$^{14,18,19}$ Furthermore, its accuracy in detecting endoleak has been found to be equivalent to that of magnetic resonance angiography (MRA) and CTA albeit in a small cohort study. ${ }^{15}$ CEUS is more sensitive to blood flow direction, allowing dynamic, real-time visualization of both inflow and outflow arteries and hence improving identification and classification of endoleaks. ${ }^{20}$ CEUS, therefore, seems to be a feasible tool in the long-term surveillance after EVAR, and may better classify endoleaks missed by DUSS. Three-dimensional (3D) CEUS has also shown excellent correlation with CTA $(r=0.935 ; P<0.0001),{ }^{21}$ however, its role in the diagnosis of endoleak remains unclear.

MRA has superior resolution and soft tissue differentiation and is therefore highly accurate in both diagnosing and classifying endoleaks. ${ }^{22}$ However, this imaging is not widely available and is both costly and time consuming, making it a less favored choice for EVAR surveillance. CTA is generally considered the gold standard in assessing endoleaks; however, due to its associated risks, many centers employ DUSS as first approach, followed by CTA to confirm or clarify any kind of complications seen.

The advantage of CT resides in its ability to acquire timely images from a number of different "phases". Noncontrast 


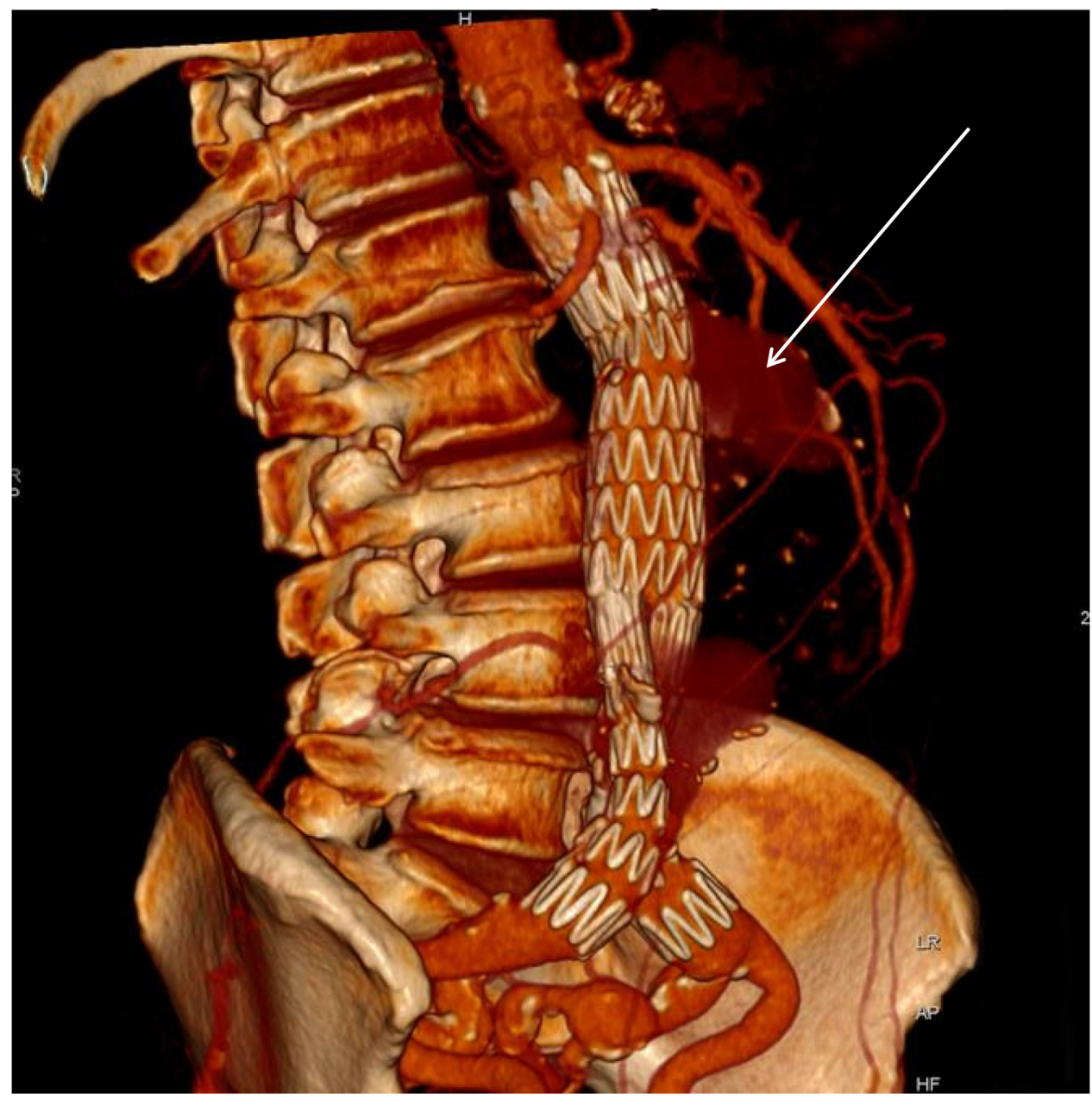

Figure 2 Reconstructed computed tomography demonstrating two type II endoleaks (arrow) seen as a blush anterior to the aortic stent graft.

images are acquired first to detect high attenuating structures such as calcium or mural thrombus. Arterial and delayed phases are then used to visualize arterial structures and "late" events such as endoleaks, which are not necessarily visible during the arterial phase. Although this approach is sensitive in the detection of endoleaks, it precludes a higher radiation exposure than alternative methods such as dual-energy CT.

Dual-energy CT acquires datasets at two different photon spectra in a single acquisition, and hence a single contrastenhanced acquisition yields both enhanced and nonenhanced data. It can be used to detect endoleaks with good accuracy and at a reduced radiation exposure. ${ }^{23,24}$ Chandarana et al detected six type II endoleaks using dual-energy acquisition. This was concordant with the data obtained from standard three-phase protocols, and radiation dose was reduced from $27.8 \mathrm{mSv}$ to $11.1 \mathrm{mSV}^{24}$

Similarly, Ascenti et al ${ }^{25}$ demonstrated a $28 \%$ reduction in radiation dose when comparing standard unenhanced and venous phase imaging (session 1) with virtual unenhanced and venous phase images with a colored iodine overlay (session 2). Both sessions detected 31 endoleaks in 74 patients, with $80.6 \%$ of these being type II leaks. Dualenergy CT may be used to detect endoleaks with good accuracy and at a reduced radiation exposure. ${ }^{23,24}$

\section{Type II endoleak and sac expansion}

Current guidelines recommend intervention in patients with type II endoleak when the sac diameter is more than $10 \mathrm{~mm} .{ }^{13}$ Type II endoleaks appear to be an independent risk factor for sac expansion; ${ }^{7,26-28}$ for example, Cieri et al demonstrated a significantly higher proportion of aneurysm growth of over $5 \mathrm{~mm}$ in their type II endoleak cohort $(P \leq 0.0001) .{ }^{28} \mathrm{Sac}$ expansion over $5 \mathrm{~mm}$ was present in $15.1 \%$ of the patients in type II endoleak group in comparison to only $1.9 \%$ in the control group at 36 months follow-up.

Jones et al demonstrated freedom from sac enlargement $(<5 \mathrm{~mm})$ at 5 -year follow-up in $94.9 \%$ of those without, compared with only $28 \%$ of those with, a type II endoleak. ${ }^{27}$ 
Furthermore, they reported no significant difference in aneurysm-associated mortality $(P=0.12)^{27}$ between those with and without type II endoleak. Similarly, El Batti et al concluded that sac expansion was most common in those patients with persistent type II endoleak. ${ }^{12}$ Another approach to understanding the risk of type II endoleak is measuring sac volume rather than size. Persistent endoleaks have been associated with inferior sac regression; for example, Kray et al demonstrated an $18 \%$ sac volume regression in the control group compared to only $5 \%$ in those with persistent type II endoleak. ${ }^{29}$

Although type II endoleak appears to be associated with sac expansion (volume changes), the significance of this expansion on risk of aneurysm rupture remains unclear. Wyss et al found a significant association between sac expansion and rupture. ${ }^{11}$ Twenty-seven ruptures occurred in an EVAR population of 848 patients, with an average follow-up of 4.8 years. Sixty-three percent of these ruptures occurred more than 30 days post-repair and were associated with prior complications detected on follow-up imaging. Five of these 17 ruptures demonstrated evidence of type II endoleak with associated sac expansion (four were isolated type II endoleaks and one was associated with a concomitant type Ib endoleak). ${ }^{11,27}$ Conversely, other authors have shown no correlation. For example, Van Marrewijk et al demonstrated that sac expansion was significantly associated with type II endoleaks; however, there was no correlation with rupture or increase in aneurysm-associated mortality. ${ }^{26-30}$ A recent systematic review article reported a low incidence of rupture in patients with isolated type II endoleaks (under 1\%) of which $57 \%$ were associated with sac expansion. ${ }^{7}$ Sac expansion may therefore be a poor marker of risk in this population of patients; however, we do not currently have a more sensitive way of monitoring risk of rupture. As such, some authors suggest that consideration should be given to prevention of/ or treatment for type II endoleak.

There is much debate regarding the significance of intrasac pressure and the benefit of monitoring such parameters. Some studies have suggested that blood pressure in the type II endoleak cavity may approach that of the systemic circulation. In a cohort of 17 patients with endoleaks, Baum et al found universally raised pressures and associated arterial waveforms. In 15 of these patients, pressure was equal to that of the systemic circulation. ${ }^{31}$ Furthermore, a high systolic pressure index (systolic sac pressure divided by arterial systolic pressure) has been shown to significantly correlate with persistent type II endoleaks over a follow-up of 12 months. ${ }^{32}$ Conversely, a systematic review by Hinnen et al concluded that the presence of a type II endoleak had no significant bearing on the natural progression of intrasac pressure. ${ }^{33}$ Indeed, the mean pressure index (mean sac pressure divided by mean arterial pressure) decreased during follow-up despite the presence of a persisting endoleak. ${ }^{33}$ Sac pressure shows a trend toward increase with increasing aneurysm diameter; however, as demonstrated by Dias et al in a cohort of six patients with type II endoleak, the pressure difference is highly variable. ${ }^{34}$ None of the aforementioned studies used rupture as an outcome measure.

Sac expansion and/or need for intervention may be predictable based on the results of CT imaging. For example, Keedy et al ( 58 type II endoleaks, 23 requiring reintervention for aneurysm sac expansion and 35 with stable sac diameters) revealed that the transverse diameter of the endoleak cavity showed a significant association with need for reintervention $(P=0.007)$. Furthermore, a threshold value of $1.42 \mathrm{~cm}$ resulted in a positive predictive value of 0.71 and a negative predictive value of 0.82 when determining which patients required reintervention. ${ }^{35}$ The maximum diameter of the communicating vessel also reached significance. Similarly, Müller-Wille et al demonstrated that the strongest indicators for aneurysm sac enlargement were complex type II endoleak (involving the inferior mesenteric artery [IMA] and lumbar arteries) and the diameter of the largest feeding and/or draining artery. ${ }^{36}$

\section{Prevention of type II endoleak}

Sac expansion and type II endoleak are possible contributory factors in late rupture after EVAR. There are several risk factors (Table 3 ) for the development of type II endoleak, which include: number of patent lumbar arteries, diameter of lumbar arteries (larger arteries tend to be associated with persistent endoleak, while lumbar arteries $<2 \mathrm{~mm}$ appear to cause a transient endoleak), patency of the IMA, proportion of aneurysm sac lined with thrombus, and maximum thrombus thickness. ${ }^{37,38}$ Güntner et al found that patients with a type II endoleak arising from the IMA

Table 3 Risk factors versus protective factors for type II endoleak

\begin{tabular}{ll}
\hline Protective factors & Risk factors \\
\hline Smoking & Patent lumbar arteries \\
Peripheral vascular disease & Diameter of lumbar arteries \\
& Patent inferior mesenteric artery \\
& Proportion of aneurysm sac lined with \\
& thrombus \\
& Maximum thrombus thickness \\
& Older age $(>80$ years) \\
\hline
\end{tabular}


had a significantly greater aortic cross-sectional area at the IMA ostium $(P<0.001)$ and also had significantly more patent aortic side branches prior to EVAR $(P<0.001){ }^{39}$ These variables were still statistically significant when analyzed using a multivariate logistic regression model. No patient with a preoperatively occluded or embolized IMA (26 of 322) developed a type II endoleak arising from this vessel. ${ }^{39}$ As such, some centers advocate preoperative or intraoperative embolization of patent aortic side branches to prevent a type II endoleak.

Fabre et $\mathrm{al}^{40}$ describe their experience of performing an intraoperative coil embolization of the aortic sac, in which they position a microcatheter between the aortic and aneurysm wall, inject $30 \mathrm{~cm}$ long coils (Interlock Fibered IDC Occlusion System; Boston Scientific, Marlborough, MA, USA), and stop the procedure after complete obliteration of the aortic sac. In their study, the mean cost of embolization was US $\$ 1,100$ for the coils, US\$90 for the catheter, and US $\$ 200$ for the additional operating room time. Among the 83 patients, one developed a type II endoleak and none of the patients developed ischemic complications, paraplegia, or renal failure. The sac diameter was significantly reduced at 6 ( $P=0.001), 12$ ( $P=0.001)$, and 24 months $(P=0.001)$ compared to the control population. ${ }^{40}$ Velazquez et a ${ }^{41}$ demonstrated in another small cohort (eleven patients) that nine (82\%) of the eleven IMA-related endoleaks were successfully embolized by selective embolization. Parry et $\mathrm{al}^{42}$ similarly reported that IMA embolization was successful in 13 of 16 patients (81\%), while lumbar embolization was successful in eight of 13 patients $(62 \%)$, with no type II endoleaks. Ward et al demonstrated $100 \%$ technical success in an IMA embolization cohort of 108 patients. ${ }^{43}$ In a 24-month follow-up period, $34 \%$ of embolized patients and $49 \%$ of nonembolized patients developed type II endoleaks. However, increase in sac volume was significantly reduced in the embolized group compared to nonembolized group ( $26 \%$ vs $47 \% ; P=0.03$ ). Preoperative embolization was also associated with significantly fewer secondary interventions (one of 108 patients vs 12 of $158 ; P=0.13)$, the only recorded fatality being a complication of mesenteric ischaemia. ${ }^{43}$ Müller-Wille et al utilized the Amplatzer Vascular Plug type 4 (AVP-4) and found initial technical success (complete occlusion of the IMA) in 29 of 31 patients (two patients requiring additional Gelfoam to form an adequate seal). Plug sizes varied from 5 to $8 \mathrm{~mm}$ and were deliberately oversized by $50 \%-100 \%$ with respect to the subject anatomy. There was a significant reduction in IMA-lumbar type II endoleaks when compared with a control population $(0 / 31$ vs $11 / 43 ; P=0.002)$. In the embolized population, six early type II endoleaks were identified secondary to flow from lumbar arteries, and this was comparable with the incidence in the control group $(6 / 31$ vs $3 / 43 ; P=0.15){ }^{44}$

Conversely, Gould et al found no significant difference in incidence of type II endoleaks after perioperative embolization but did note that during follow-up, the mean change in sac diameter was $-0.5 \mathrm{~mm}$ in the embolized group compared to $+3.11 \mathrm{~mm}$ in nonembolized population..$^{45}$ Furthermore, Piazza et al reported the use of a standardized dose of fibrin glue and coils for sac embolization prior to EVAR and demonstrated that the lower incidence of type II endoleak in the embolized group was transient and by 18 months there was no longer a statistically significant difference. There was also no significant difference in sac volume increase. ${ }^{46}$

An alternative technique has been described by Burbelko et $\mathrm{al}^{47}$ who evaluated the feasibility of visceral and/or lumbar artery embolization using Amplatzer plugs prior to EVAR. In their case series, all of the procedures were performed under local anesthetic via femoral access. The target vessel was catheterized using an angiographic catheter before a plug was introduced (diameter 30\%-50\% larger than the target artery diameter), and correct plug position was ensured. Although small (33 patients), this study presents a $100 \%$ rate of target vessel occlusion with no endoleak on CT follow-up.

These results demonstrate that preoperative/intraoperative embolization of aortic side branches is technically feasible, with variable success rates. However, this procedure is associated with some disadvantages, for example, longer procedure duration, longer fluoroscopy times, risk of coil dislocation leading to nontarget embolization, and higher costs. Given that many type II endoleaks spontaneously thrombose given time,${ }^{10}$ these risks may outweigh any benefit gained.

\section{Conservative management}

Many authors believe that type II endoleaks are benign. Greenhalgh et al concluded that type II endoleaks are not associated with aneurysm rupture, drawing data of over 2,000 patients from the EUROSTAR registry ${ }^{26}$ which found a $1.8 \%$ rupture rate after 2 years, with no significant difference between those with or without type II endoleaks. ${ }^{3}$ Moreover, several studies have demonstrated a reasonable rate of spontaneous resolution of type II endoleaks with figures ranging from $35.4 \%{ }^{7}$ to $80 \% .{ }^{27} \mathrm{~A}$ recent meta-analysis comprising over 2,000 patients reported resolution of over $50 \%$ of type II endoleaks within 1 year of follow-up. ${ }^{8}$ One systematic review ${ }^{10}$ reported that from 1,515 isolated type II endoleaks, $35.4 \%$ resolved spontaneously with an overall 
rupture rate of $0.9 \%$. Similarly, Silverberg et al found that 55 of 154 patients with endoleaks demonstrated spontaneous resolution within an average of 14.5 months and that three-quarters of all type II endoleaks appeared to resolve spontaneously within 5 years. ${ }^{48}$

Sidloff et al in a retrospective single-center review demonstrated that $19 \%$ of patients developed type II endoleak over a median follow-up of 3.6 years, of which $54 \%$ spontaneously resolved within 6 months. ${ }^{10}$ Importantly, no difference was seen in aneurysm-related mortality or the rate of type II endoleak between the group with and without type II endoleak (suggesting no association between type II endoleak and graft migration). ${ }^{10}$ Taken together, these findings suggest a reasonable chance for type II endoleaks to thrombose spontaneously.

Walker et $\mathrm{al}^{49}$ recently reported - from a large multicenter registry including 1,736 patients - a median follow-up of over 32.2 months (interquartile range, 14.2-52.8 months). Their study demonstrated no difference in the overall all-cause mortality $(P=0.26)$ or aneurysm-associated mortality $(P=0.47)$ between patients who underwent reintervention and those in whom type II endoleaks were treated conservatively. ${ }^{49}$ Similarly, Karthikesalingam et $\mathrm{al}^{50}$ also demonstrated no significant reduction in sac expansion $(P=0.60)$ or improvement in sac regression $(P=0.69)$ when compared to patients treated conservatively (no intervention), selectively ( $>5 \mathrm{~mm}$ sac expansion or persistent endoleak over 6 months), or aggressively (any type II endoleak or those persisting for $>3$ months). ${ }^{50}$

Walker et $\mathrm{al}^{49}$ analyzed 91 lumbar embolizations, 49 additional stents, and 29 direct sac injections for type II endoleaks. These reinterventions were technically successful in only $31.5 \%$ of the patients. Among the 82 patients who underwent reintervention for sac growth, $45.1 \%$ continued to have sac growth. The relatively poor success rate of interventions has previously been noted in several studies. Taken together, the available evidence has led many centers to adopt a conservative approach to the treatment of type II endoleak with minimal sac expansion.

\section{Post-EVAR embolization of type II endoleaks}

Several methods to embolize troublesome side branches and prevent type II endoleaks have been described. Classically, the transarterial technique involves selectively embolizing the IMA (via the middle colic artery) or the feeding lumbar artery (via the iliolumbar artery) as appropriate. ${ }^{51}$ This may involve embolizing only the feeding artery, the aneurysm cavity itself, or both. The translumbar technique ${ }^{52}$ involves
Table 4 Classes of embolents

\begin{tabular}{|c|c|}
\hline Embolent & Mechanism of action \\
\hline Coils & $\begin{array}{l}\text { Reduce blood flow inducing thrombosis } \\
\text { Cause vessel wall damage }\end{array}$ \\
\hline Amplatzer Vascular Plug & $\begin{array}{l}\text { Plug the vessel wall, damaging the wall and } \\
\text { promoting thrombogenesis }\end{array}$ \\
\hline $\begin{array}{l}\text { Particulate embolization } \\
\text { agents }\end{array}$ & $\begin{array}{l}\text { Reduce blood flow, initiating thrombosis } \\
\text { and promoting angionecrosis of the vessel } \\
\text { wall }\end{array}$ \\
\hline Gelatin foam/powder & $\begin{array}{l}\text { Forms a cast of the vessel forming a } \\
\text { surface for thrombogenesis and occlusion }\end{array}$ \\
\hline Tissue adhesives (glue) & $\begin{array}{l}\text { Forms a cast of the vessel and incites an } \\
\text { inflammatory response }\end{array}$ \\
\hline Sclerosing agents & $\begin{array}{l}\text { Directly toxic to the tissues, inducing } \\
\text { tissue necrosis }\end{array}$ \\
\hline
\end{tabular}

inserting a 19-gauge, $20 \mathrm{~cm}$ needle, under CT fluoroscopic guidance, through the right flank at the level of the endoleak, approximately 4-5 finger breaths from the posterior midline as measured from the spinous processes. The aneurysm sac is punctured, and endoleak is identified and embolized. Classes of embolic agent are described in Table 4.

\section{Transarterial embolotherapy}

Percutaneous transarterial embolization is the most common first-line approach when treating type II endoleak. Transbrachial or transfemoral access may be used to access the inferior mesenteric or lumbar arteries via the superior mesenteric or internal iliac arteries, ${ }^{16}$ respectively. A recent systematic review reported a $62.5 \%$ overall success rate in 120 transarterial procedures ${ }^{10}$ however, clinical success, which has been defined as no recurrent type II endoleak, appears to be highly variable with rates ranging from $15 \%{ }^{53}$ to $89 \% .{ }^{54}$ Haulon et al were successfully able to embolize 17 of 18 patients with type II endoleak (two were treated with coils, 15 patients with biological glue, and one patient with biological glue and microparticles). ${ }^{54}$ In their cohort, only two recurrent type II endoleaks were identified over a mean follow-up of 13.3 months. The aneurysm sac reduced in 13 patients $(72 \%)$ and remained unchanged in five. ${ }^{54}$

Bosiers et $\mathrm{al}^{55}$ reported midterm results (19.8 months, range 3-31 months), using Onyx in patients with persistent type II endoleak and sac growth $>5 \mathrm{~mm}$. Onyx is a liquid embolic agent (ethylene vinyl alcohol copolymer dissolved in dimethyl sulfoxide) They included ten patients (13 endoleaks), of which 12 were successfully cannulated and all those had stable or reducing aneurysm sac size post-procedure. They also reported a rupture of the hypogastric artery (treated with a covered stent) and in one patient, extravasation of Onyx out of the aneurysm sac into the inferior vena cava. 
Similarly, Abularrage et a ${ }^{56}$ demonstrated significantly higher medium-term success in those managed with Onyx. Onyx glue embolization was associated with a greater success rate when used as the initial secondary intervention (odds ratio, 59.61; 95\% confidence interval, 4.78-742.73; $P<0.001$ ), and the mean change in aneurysm sac diameter during follow-up was decreased in the Onyx glue embolization group compared to the non-Onyx group.

Sarac et $\mathrm{al}^{57}$ have published long-term outcomes for patients undergoing embolization procedures for type II endoleak. This included 95 patients (140 embolization procedures). In this cohort, they utilized glue (61\%), coils (29\%), glue and coils (7\%), and Gelfoam (3\%; Pfizer Inc., New York, NY, USA), revealing that $20 \%$ required further reintervention. These authors felt that coil embolization alone seemed to result in more secondary procedures being performed.

In contrast, Baum et $\mathrm{al}^{53}$ identified that recanalization of the original endoleak occurred in 16 of 20 superselective IMA embolizations when using microcoils. Postulated reasons for clinical failure include development of a retiform anastomosis, a new mesenteric leak after occlusion of the iliolumbar vasculature, or persistent flow through coils,$^{58}$ possibly due to concurrent oral anticoagulation therapy. ${ }^{59}$

Several other techniques have been described. TorresBlanco et al reported a case of a 67-year-old male with a significant increase in sac diameter up to $96 \mathrm{~mm}$ and a previously failed IMA embolization. ${ }^{60}$ Using a femoral approach, the guidewire was passed between the iliac limb of the EVAR graft and the arterial wall to gain access to the aneurysmal sac. The endoleak was packed with coils and thrombin, and a postoperative $\mathrm{CT}$ at 9 months showed marked decrease in the size of the aneurysm. ${ }^{60}$

Study design varies greatly with some centers aggressively treating $^{50,59}$ all endoleaks irrespective of sac expansion, ${ }^{53,54,61}$ while others only treat secondary or persistent endoleaks. ${ }^{62}$ In addition, length of follow-up is generally poor, ranging from a matter of weeks ${ }^{63}$ up to 2 years. ${ }^{54,61}$ Poor results from transarterial intervention is mainly due to not "treating" the nidus of the endoleak. Kasirajan et al noted that failure was often the result of being unable to reach and coil the aneurysm sac, ${ }^{59}$ while Müller-Wille et al similarly suggested that "To achieve the best clinical results, complete occlusion of the nidus is mandatory." ${ }^{14}$ Future studies should aim to compare different embolents (in addition to techniques) in order to better understand the gold standard treatment when trying to thrombose a type II endoleak.

\section{Translumbar and direct sac embolotherapy}

Translumbar embolization and direct sac puncture are technically similar and involve advancing a needle through the retroperitoneum at the level of the endoleak under direct fluoroscopic guidance. ${ }^{10}$ It has been suggested that this intervention may lead to lower reintervention rates than its transarterial counterpart, ${ }^{53}$ with a recent systematic review suggesting a $76 \%$ success rate ${ }^{10}$ however, in many studies, the translumbar approach was a second-line treatment, and therefore these findings require further investigation.

Uthoff et al conducted a single-center retrospective analysis of 19 type II endoleaks treated via a translumbar approach, and they demonstrated an initial technical success rate of $>88 \%$; however, half of these patients were found to have a recurrent endoleak after 39 months of follow-up and two-thirds of these required a secondary procedure. ${ }^{65,66}$

Various complications have been reported, the most clinically significant being a pulmonary embolus secondary to extravasation of glue in the inferior vena cava (IVC) and stent puncture leading to the development of a type III endoleak. ${ }^{66}$ There are few published studies involving the sole treatment of type II endoleaks via a translumbar approach; indeed, this technique is typically reserved for cases in which transarterial access has failed, and thus comparisons must be cautiously made to prevent selection bias. ${ }^{16,65}$

\section{Other techniques}

\section{Percutaneous transcaval embolization}

Success has been reported using a transcaval approach to the aneurysm sac, ${ }^{67}$ with promising 1 -year recurrence rates and regression in sac size, ${ }^{68,69}$ in addition to a significant reduction in intrasac pressure. ${ }^{70}$

Giles et a ${ }^{67}$ recently described a transcaval approach to embolizing the aneurysm sac for type II endoleaks. This procedure involves right femoral vein access, placement of a cannula into the appropriate position under intravascular ultrasound, intraoperative cone-beam $\mathrm{CT}$, and venacavogram guidance. A trocar/catheter combination is then advanced through the cannula into the sac under fluoroscopic guidance before a sac angiogram and deployment of an embolent of choice. Technical success was reported in $90 \%$ of the procedures (29 patients) with no significant adverse events, although five patients required reintervention for sac expansion. Similarly, Gandini et al ${ }^{70}$ reported their experience with percutaneous transcaval embolization (nine embolizations of the sac and 17 embolizations of the feeding vessels). Over a mean follow-up of $25.9 \pm 11.0$ months, four patients 
developed recurrent endoleaks; among them, three underwent reintervention and aneurysm rupture occurred in one patient. They suggest that transcaval sac embolization is the more successful procedure and that this is a feasible first-line option for the treatment of type II endoleak.

\section{Laparoscopic/Endoscopic}

In the presence of adverse features, for example, sac expansion, some centers advocate more invasive options including laparoscopic ${ }^{71}$ or open surgical repair. ${ }^{72}$ Touma et $\mathrm{al}^{73}$ described a laparoscopic left transperitoneal retrorenal approach to the infrarenal aorta. The authors advocate avoiding close dissection of the sac and starting with dissection and ligation of the IMA at a distance of $2 \mathrm{~cm}$ from the wall of the sac. Lumbar arteries are approached in the plane of the lumbar anterior longitudinal ligament before a laparoscopic clamp is placed at the aneurysm neck (in case of occult high-pressure endoleaks), then the sac is opened and thrombus is emptied to confirm no back bleeding. Kolvenbach et al proposed a similar technique in $2002 .^{74}$

Voûte et $\mathrm{al}^{75}$ described their experience with endoscopic sac "fenestration". This technique involves clipping all visible lumbar arteries through a retroperitoneal approach, with the IMA clipped laparoscopically (if necessary). Subsequently, the aneurysm was fenestrated allowing them to check for back bleeding and suture any remaining type II endoleaks. No perioperative deaths occurred in the eight patients reported over a median follow-up of 6.6 (range 0.6-8.6) years; however, only three patients experienced durable aneurysm sac shrinkage or stability. Wisselink et $\mathrm{al}^{76}$ reported a similar approach in a case report in which a postoperative CT scan revealed an unclipped lumbar artery just proximal to the aortic bifurcation requiring reoperation.

\section{Open approach}

In cases where there are adverse features for a laparoscopic approach, an open approach may be considered. The "sacotomy" technique was first described in $2002,{ }^{77}$ requiring a midline laparotomy to expose the aneurysm sac that was subsequently opened. Bleeding vessels were over-sewn (with a nonabsorbable suture) before the sac was closed without the need for aortic clamping. Faccenna et $\mathrm{al}^{78}$ reported two cases of sacotomy (one aneurysm rupture and one elective case after several unsuccessful endovascular procedures) via a midline laparotomy. Similarly, sacotomy was used to identify the bleeding sources without aortic cross-clamping and/or endograft explanation.
In a review of 26 articles comprising 641 patients, the most common indication for open conversion was endoleak (62.4\%), with type II endoleak comprising $26.8 \%$ of all cases with an overall mortality of $3.2 \% .{ }^{79}$ Klonaris et al recently reported upon failure of endovascular aneurysm repair and the subsequent need for late open conversion. Eighteen patients underwent open conversion, ten of these secondary to a persistent type II endoleak with associated sac expansion. Six of these patients were able to undergo simple ligation of the culprit vessels, with no aortic cross-clamping and complete preservation of the original stent (attempted transarterial coil embolization had previously failed in two-thirds of these patients). The remaining four patients with type II endoleak required graft revision due to either iatrogenic damage or complete graft occlusion. Three of the 18 patients required emergency surgery with two cases of rupture: one due to a type Ia endoleak (resulting in the only perioperative fatality in the series) and the other secondary to a new-onset type II endoleak arising from the IMA. ${ }^{80}$

\section{Future possibilities - endovascular aneurysm sealing}

Endovascular aneurysm sealing (Nellix ${ }^{\mathrm{TM}}$, Endologix, California, USA) has been developed with an appreciation that the persistent aneurysm sac post-EVAR is the most common cause of many post-EVAR complications including type II endoleak. Nellix ${ }^{\mathrm{TM}}$ utilizes polymer-filled endobags surrounding balloon-expandable stents that are covered with expanded polytetrafluoroethylene. These endobags are filled with a polyethylene glycol-based polymer containing $1 \%$ radiopaque contrast, which fills the remaining aneurysm sac, completely sealing the lumen. This mechanism should in theory completely exclude aortic side branches from the remaining sac, preventing type II endoleak.

A recent multicenter report (Europe and New Zealand), inclusive of 171 patients with a median follow-up of 5 months (range 0-14 months), noted that at final follow-up, four patients had developed type II endoleak, which constitutes $2 \%$ of the cohort. ${ }^{81}$ Although this suggests a lower incidence of type II endoleak when using endovascular aneurysm sealing, this result should be interpreted with caution due to the small follow-up time.

Brownrigg et $\mathrm{al}^{82}$ presented a single-center report of 105 patients treated with Nellix ${ }^{\text {TM }}$ (2013-2014). Within their study, there were no type II endoleaks noted; however, only 30-day outcomes were presented. De Bruin et al ${ }^{83}$ assessed the feasibility of using endovascular aneurysm sealing in ruptured aneurysm. Although this study was small (five patients), 
there were no type II endoleaks in those who survived (three patients). One patient with a type 1 endoleak following insertion of a Nellix ${ }^{\mathrm{TM}}$ graft underwent an attempted embolization with Onyx. This was further complicated by the migration of Onyx into the stent limb causing a significant limb stenosis and requiring placement of a covered stent. ${ }^{69}$ The role of endovascular aneurysm sealing is yet to be fully understood, and although promising, the Nellix EVAS FORWARD Global Registry and the EVAS FORWARD investigational device exemption trial are ongoing.

\section{Conclusion}

Endoleak remains the Achilles' heel of EVAR. As the available evidence suggests that type II endoleaks have a reasonable chance of thrombosing spontaneously and that many do not cause sac expansion with its associated risk of complications, many have adopted a conservative approach to the treatment of type II endoleak with minimal sac expansion (under $10 \mathrm{~mm}$ ).

Due to a lack of evidence regarding the natural history of type II endoleaks and their association with adverse outcomes such as sac expansion and rupture, intervention is typically offered for persistent endoleaks and for those which demonstrate sac expansion $(>10 \mathrm{~mm})$ or increased intrasac pressure. Unfortunately, optimal thresholds are not clear. ${ }^{50}$ Taken together, with relatively high reintervention rates, ${ }^{53,56}$ a careful risk versus benefit review is important in addition to careful imaging to confirm there is no highpressure endoleak (Figure 3).

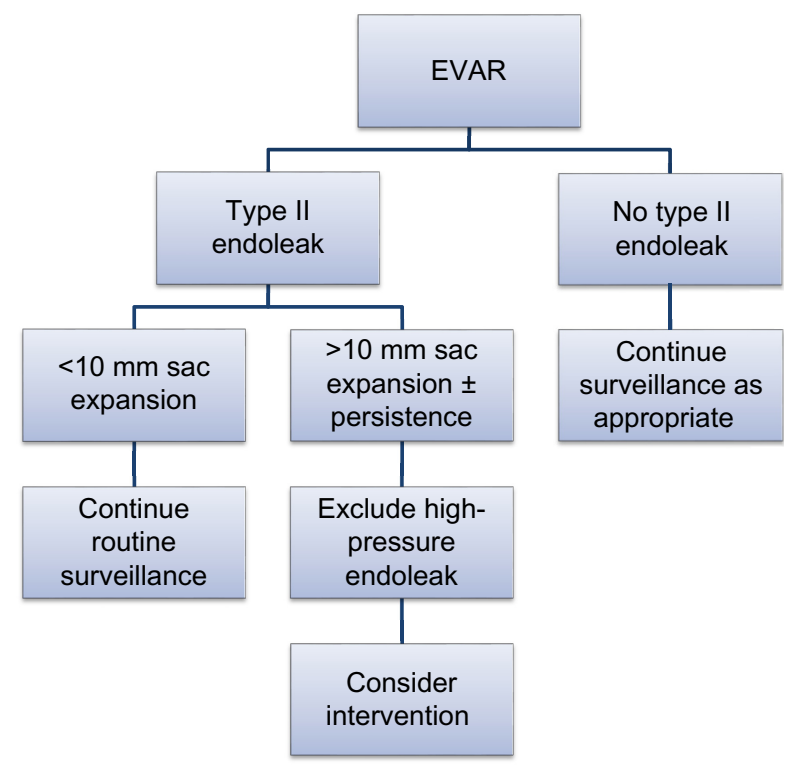

Figure 3 Proposed management of type II endoleak.

Abbreviation: EVAR, endovascular abdominal aortic aneurysm repair.
The event rate of complications in patients with type II endoleak remains low. Therefore, large numbers of patients would be required in well-designed trials to examine outcomes in this challenging group of patients. Future studies should aim to compare not only different approaches to the treatment of type II endoleak, but also different embolents. More focus is needed on long-term outcomes and complications rather than technical success alone. A multicenter registry of type II endoleak intervention and outcomes would be ideal to uncover solutions to some of the remaining challenges in the management of this challenging group of patients.

\section{Disclosure}

The authors report no conflicts of interest in this work.

\section{References}

1. Lederle FA, Freischlag JA, Kyriakides TC, et al. Long-term comparison of endovascular and open repair of abdominal aortic aneurysm. $N$ Engl J Med. 2012;367(21):1988-1997.

2. Stather PW, Sidloff D, Dattani N, Choke E, Bown MJ, Sayers RD. Systematic review and meta-analysis of the early and late outcomes of open and endovascular repair of abdominal aortic aneurysm. Br J Surg. 2013;100(7):863-872.

3. Greenhalgh RM, Brown LC, Powell JT, et al. Endovascular versus open repair of abdominal aortic aneurysm. $N$ Engl J Med. 2010;362(20):1863-1871.

4. De Bruin JL, Baas AF, Buth J, et al. Long-term outcome of open or endovascular repair of abdominal aortic aneurysm. $N$ Engl J Med. 2010;362(20):1881-1889.

5. Becquemin JP, Pillet JC, Lescalie F, et al. A randomized controlled trial of endovascular aneurysm repair versus open surgery for abdominal aortic aneurysms in low- to moderate-risk patients. J Vasc Surg. 2011;53(5):1167-1173.e1.

6. Dangas G, O'Connor D, Firwana B, et al. Open versus endovascular stent graft repair of abdominal aortic aneurysms: a meta-analysis of randomized trials. JACC Cardiovasc Interv. 2012;5(10):1071-1080.

7. Sidloff DA, Gokani V, Stather PW, Choke E, Bown MJ, Sayers RD. Type II endoleak: conservative management is a safe strategy. Eur $J$ Vasc Endovasc Surg. 2014;48(4):391-399.

8. Gelfand DV, White GH, Wilson SE. Clinical significance of type II endoleak after endovascular repair of abdominal aortic aneurysm. Ann Vasc Surg. 2006;20(1):69-74.

9. Choke E, Thompson M. Endoleak after endovascular aneurysm repair: current concepts. J Cardiovasc Surg (Torino). 2004;45(4):349-366.

10. Sidloff DA, Stather PW, Choke E, Bown MJ, Sayers RD. Type II endoleak after endovascular aneurysm repair. Br J Surg. 2013;100(10):1262-1270.

11. Wyss TR, Brown LC, Powell JT, Greenhalgh RM. Rate and predictability of graft rupture after endovascular and open abdominal aortic aneurysm repair: data from the EVAR Trials. Ann Surg. 2010;252(5):805-812.

12. El Batti S, Cochennec F, Roudot-Thoraval F, Becquemin JP. Type II endoleaks after endovascular repair of abdominal aortic aneurysm are not always a benign condition. J Vasc Surg. 2013;57(5):1291-1297.

13. Moll FL, Powell JT, Fraedrich G, et al. Management of abdominal aortic aneurysms clinical practice guidelines of the European society for vascular surgery. Eur J Vasc Endovasc Surg. 2011;41 (Suppl 1):S1-S58.

14. Mirza TA, Karthikesalingam A, Jackson D, et al. Duplex ultrasound and contrast-enhanced ultrasound versus computed tomography for the detection of endoleak after EVAR: systematic review and bivariate meta-analysis. Eur J Vasc Endovasc Surg. 2010;39(4):418-428. 
15. Cantisani V, Ricci P, Grazhdani H, et al. Prospective comparative analysis of colour-Doppler ultrasound, contrast-enhanced ultrasound, computed tomography and magnetic resonance in detecting endoleak after endovascular abdominal aortic aneurysm repair. Eur J Vasc Endovasc Surg. 2011;41(2):186-192.

16. Avgerinos ED, Chaer RA, Makaroun MS. Type II endoleaks. $J$ Vasc Surg. 2014;60(5):1386-1391.

17. Nagre SB, Taylor SM, Passman MA, et al. Evaluating outcomes of endoleak discrepancies between computed tomography scan and ultrasound imaging after endovascular abdominal aneurysm repair. Ann Vasc Surg. 2011;25(1):94-100.

18. Gürtler VM, Sommer WH, Meimarakis G, et al. A comparison between contrast-enhanced ultrasound imaging and multislice computed tomography in detecting and classifying endoleaks in the follow-up after endovascular aneurysm repair. J Vasc Surg. 2013;58(2):340-345.

19. Iezzi R, Basilico R, Giancristofaro D, Pascali D, Cotroneo AR, Storto ML. Contrast-enhanced ultrasound versus color duplex ultrasound imaging in the follow-up of patients after endovascular abdominal aortic aneurysm repair. J Vasc Surg. 2009;49(3):552-560.

20. Picel AC, Kansal N. Essentials of endovascular abdominal aortic aneurysm repair imaging: postprocedure surveillance and complications. AJR Am J Roentgenol. 2014;203(4):W358-W372.

21. Abbas A, Hansrani V, Sedgwick N, Ghosh J, McCollum CN. 3D contrast enhanced ultrasound for detecting endoleak following endovascular aneurysm repair (EVAR). Eur J Vasc Endovasc Surg. 2014;47(5):487-492.

22. Habets J, Zandvoort HJ, Reitsma JB, et al. Magnetic resonance imaging is more sensitive than computed tomography angiography for the detection of endoleaks after endovascular abdominal aortic aneurysm repair: a systematic review. Eur J Vasc Endovasc Surg. 2013;45(4):340-350.

23. Song KD, Kim CK, Park BK, Kim B. Utility of iodine overlay technique and virtual unenhanced images for the characterization of renal masses by dual-energy CT. AJR Am J Roentgenol. 2011;197(6):W1076-1082.

24. Chandarana H, Godoy MC, Vlahos I, et al. Abdominal aorta: evaluation with dual-source dual-energy multidetector $\mathrm{CT}$ after endovascular repair of aneurysms - initial observations. Radiology. 2008;249(2):692-700.

25. Ascenti G, Mazziotti S, Lamberto S et al. Dual-energy CT for detection of endoleaks after endovascular abdominal aneurysm repair: usefulness of colored iodine overlay. AJR Am J Roentgenol. 2011;196(6):1408-1014.

26. van Marrewijk CJ, Fransen G, Laheij RJ, Harris PL, Buth J, Collaborators E. Is a type II endoleak after EVAR a harbinger of risk? Causes and outcome of open conversion and aneurysm rupture during follow-up. Eur J Vasc Endovasc Surg. 2004;27(2):128-137.

27. Jones JE, Atkins MD, Brewster DC, et al. Persistent type 2 endoleak after endovascular repair of abdominal aortic aneurysm is associated with adverse late outcomes. J Vasc Surg. 2007;46(1):1-8.

28. Cieri E, De Rango P, Isernia G, et al. Type II endoleak is an enigmatic and unpredictable marker of worse outcome after endovascular aneurysm repair. J Vasc Surg. 2014;59(4):930-937.

29. Kray J, Kirk S, Franko J, Chew DK. Role of type II endoleak in sac regression after endovascular repair of infrarenal abdominal aortic aneurysms. J Vasc Surg. 2015;61(4):869-874.

30. Nolz R, Schwartz E, Langs G, et al. Stent graft surface movement after infrarenal abdominal aortic aneurysm repair: comparison of patients with and without a Type 2 endoleak. Eur JVasc Endovasc Surg. 2015;50(2):181-188.

31. Baum RA, Carpenter JP, Cope C, et al. Aneurysm sac pressure measurements after endovascular repair of abdominal aortic aneurysms. J Vasc Surg. 2001;33(1):32-41.

32. Ikoma A, Nakai M, Sato M, et al. Systolic Sac Pressure Index for the Prediction of Persistent Type II Endoleak for 12 Months After Endovascular Abdominal Aortic Aneurysm Repair. Cardiovasc Intervent Radiol. Epub 2015 Sep 10.

33. Hinnen JW, Koning OH, van Bockel JH, Hamming JF. Aneurysm sac pressure after EVAR: the role of endoleak. Eur J Vasc Endovasc Surg. 2007;34(4):432-441; discussion 42-43.
34. Dias NV, Ivancev K, Malina M, Resch T, Lindblad B, Sonesson B. Intra-aneurysm sac pressure measurements after endovascular aneurysm repair: differences between shrinking, unchanged, and expanding aneurysms with and without endoleaks. J Vasc Surg. 2004;39(6):1229-1235.

35. Keedy AW, Yeh BM, Kohr JR, Hiramoto JS, Schneider DB, Breiman RS. Evaluation of potential outcome predictors in type II Endoleak: a retrospective study with $\mathrm{CT}$ angiography feature analysis. AJR Am J Roentgenol. 2011;197(1):234-240.

36. Müller-Wille R, Borgmann T, Wohlgemuth WA, et al. Dual-energy computed tomography after endovascular aortic aneurysm repair: the role of hard plaque imaging for endoleak detection. Eur Radiol. 2014;24(10):2449-2457.

37. Marchiori A, von Ristow A, Guimaraes M, Schönholz C, Uflacker R. Predictive factors for the development of type II endoleaks. J Endovasc Ther. 2011;18(3):299-305.

38. Ward TJ, Cohen S, Patel RS, et al. Anatomic risk factors for type-2 endoleak following EVAR: a retrospective review of preoperative CT angiography in 326 patients. Cardiovasc Intervent Radiol. 2014;37(2):324-328

39. Güntner O, Zeman F, Wohlgemuth WA, et al. Inferior mesenteric arterial type II endoleaks after endovascular repair of abdominal aortic aneurysm: are they predictable? Radiology. 2014;270(3):910-919.

40. Fabre D, Fadel E, Brenot P, et al. Type II endoleak prevention with coil embolization during endovascular aneurysm repair in high-risk patients. J Vasc Surg. 2015;62(1):1-7.

41. Velazquez OC, Baum RA, Carpenter JP, et al. Relationship between preoperative patency of the inferior mesenteric artery and subsequent occurrence of type II endoleak in patients undergoing endovascular repair of abdominal aortic aneurysms. J Vasc Surg. 2000;32(4):777-788.

42. Parry DJ, Kessel DO, Robertson I, et al. Type II endoleaks: predictable, preventable, and sometimes treatable? J Vasc Surg. 2002;36(1):105-110.

43. Ward TJ, Cohen S, Fischman AM, et al. Preoperative inferior mesenteric artery embolization before endovascular aneurysm repair: decreased incidence of type II endoleak and aneurysm sac enlargement with 24-month follow-up. J Vasc Interv Radiol. 2013;24(1):49-55.

44. Müller-Wille R, Uller W, Gössmann H, et al. Inferior mesenteric artery embolization before endovascular aortic aneurysm repair using amplatzer vascular plug type 4. Cardiovasc Intervent Radiol. 2014;37(4):928-934.

45. Gould DA, McWilliams R, Edwards RD, et al. Aortic side branch embolization before endovascular aneurysm repair: incidence of type II endoleak. J Vasc Interv Radiol. 2001;12(3):337-341.

46. Piazza M, Frigatti P, Scrivere P, et al. Role of aneurysm sac embolization during endovascular aneurysm repair in the prevention of type II endoleak-related complications. J Vasc Surg. 2013;57(4):934-941.

47. Burbelko M, Kalinowski M, Heverhagen JT, et al. Prevention of type II endoleak using the AMPLATZER vascular plug before endovascular aneurysm repair. Eur J Vasc Endovasc Surg. 2014;47(1):28-36.

48. Silverberg D, Baril DT, Ellozy SH, et al. An 8-year experience with type II endoleaks: natural history suggests selective intervention is a safe approach. J Vasc Surg. 2006;44(3):453-459.

49. Walker J, Tucker LY, Goodney P, et al. Type II endoleak with or without intervention after endovascular aortic aneurysm repair does not change aneurysm-related outcomes despite sac growth. J Vasc Surg. 2015;62(3):551-561.

50. Karthikesalingam A, Thrumurthy SG, Jackson D, et al. Current evidence is insufficient to define an optimal threshold for intervention in isolated type II endoleak after endovascular aneurysm repair. J Endovasc Ther. 2012;19(2):200-208.

51. Stavropoulos SW, Park J, Fairman R, Carpenter J. Type 2 endoleak embolization comparison: translumbar embolization versus modified transarterial embolization. J Vasc Interv Radiol. 2009;20(10):1299-1302.

52. Stavropoulos SW, Kim H, Clark TW, Fairman RM, Velazquez O, Carpenter JP. Embolization of type 2 endoleaks after endovascular repair of abdominal aortic aneurysms with use of cyanoacrylate with or without coils. J Vasc Interv Radiol. 2005;16(6):857-861. 
53. Baum RA, Carpenter JP, Golden MA, et al. Treatment of type II endoleaks after endovascular repair of abdominal aortic aneurysms: comparison of transarterial and translumbar techniques. J Vasc Surg. 2002(35):23-29.

54. Haulon S, Tyazi A, Willoteaux S, Koussa M, Lions C, Beregi JP. Embolization of type II endoleaks after aortic stent-graft implantation: technique and immediate results. J Vasc Surg. 2001;34(4):600-605.

55. Bosiers MJ, Schwindt A, Donas KP, Torsello G. Midterm results of the transarterial use of Onyx in the treatment of persisting type II endoleaks after EVAR. J Cardiovasc Surg (Torino). 2013;54(4):469-475.

56. Abularrage CJ, Patel VI, Conrad MF, Schneider EB, Cambria RP, Kwolek CJ. Improved results using Onyx glue for the treatment of persistent type 2 endoleak after endovascular aneurysm repair. $J$ Vasc Surg. 2012;56(3):630-636.

57. Sarac TP, Gibbons C, Vargas L, et al. Long-term follow-up of type II endoleak embolization reveals the need for close surveillance. $J$ Vasc Surg. 2012;55(1):33-40.

58. Solis MM, Ayerdi J, Babcock GA, et al. Mechanism of failure in the treatment of type II endoleak with percutaneous coil embolization. J Vasc Surg. 2002;36(3):485-491.

59. Kasirajan K, Matteson B, Marek JM, Langsfeld M. Technique and results of transfemoral superselective coil embolization of type II lumbar endoleak. J Vasc Surg. 2003;38(1):61-66.

60. Torres-Blanco Á, Schmidt A, Gómez-Palonés F, Ortiz-Monzón E. The Roadside Technique for Type II Endoleak Embolization 4 Years after Endovascular Aortic Aneurysm Repair. Ann Vasc Surg. 2015;29(4):837. e13-e16.

61. Faries PL, Cadot H, Agarwal G, Kent KC, Hollier LH, Marin ML. Management of endoleak after endovascular aneurysm repair: cuffs, coils, and conversion. J Vasc Surg. 2003;37(6):1155-1161.

62. Sheehan MK, Barbato J, Compton CN, Zajko A, Rhee R, Makaroun MS. Effectiveness of coiling in the treatment of endoleaks after endovascular repair. J Vasc Surg. 2004;40(3):430-434.

63. Massis K, Carson WG, Rozas A, Patel V, Zwiebel B. Treatment of type II endoleaks with ethylene-vinyl-alcohol copolymer (Onyx). Vasc Endovascular Surg. 2012;46(3):251-257.

64. Müller-Wille R, Wohlgemuth WA, Heiss P, et al. Transarterial embolization of type II endoleaks after EVAR: the role of ethylene vinyl alcohol copolymer (Onyx). Cardiovasc Intervent Radiol. 2013;36(5):1288-1295.

65. Chung R, Morgan RA. Type 2 Endoleaks Post-EVAR: Current Evidence for Rupture Risk, Intervention and Outcomes of Treatment. Cardiovasc Intervent Radiol. 2015;38(3):507-522.

66. Uthoff H, Katzen BT, Gandhi R, Peña CS, Benenati JF, Geisbüsch P. Direct percutaneous sac injection for postoperative endoleak treatment after endovascular aortic aneurysm repair. J Vasc Surg. 2012;56(4):965-972.

67. Giles KA, Fillinger MF, De Martino RR, Hoel AW, Powell RJ, Walsh DB. Results of transcaval embolization for sac expansion from type II endoleaks after endovascular aneurysm repair. JVasc Surg. 2015;61(5): 1129-1136.

68. Mansueto G, Cenzi D, Scuro A, et al. Treatment of type II endoleak with a transcatheter transcaval approach: results at 1-year follow-up. J Vasc Surg. 2007;45(6):1120-1127.
69. Midulla M, Perini P, Sundareyan R, et al. Transcatheter transcaval embolization of a type II endoleak after EVAR using a transsepta needle-sheath system. Vasc Endovascular Surg. 2012;46(5):410-413.

70. Gandini R, Chiocchi M, Loreni G, et al. Treatment of type II endoleak after endovascular aneurysm repair: the role of selective vs. nonselective transcaval embolization. J Endovasc Ther. 2014;21(5):714-722.

71. Richardson WS, Sternbergh WC, Money SR. Laparoscopic inferior mesenteric artery ligation: an alternative for the treatment of type II endoleaks. J Laparoendosc Adv Surg Tech A. 2003;13(6):355-358.

72. Halak M, McDonnell CO, Muhlmann MD, Baker SR. Open surgical treatment of aneurysmal sac expansion following endovascular abdominal aneurysm repair: solution for an unresolved clinical dilemma. Vascular. 2007;15(4):201-204.

73. Touma J, Coscas R, Javerliat I, Colacchio G, Goëau-Brissonnière O, Coggia M. A technical tip for total laparoscopic type II endoleak repair. J Vasc Surg. 2015;61(3):817-820.

74. Kolvenbach R, Pinter L, Raghunandan M, Cheshire N, Ramadan H, Dion YM. Laparoscopic remodeling of abdominal aortic aneurysms after endovascular exclusion: a technical description. J Vasc Surg. 2002;36(6):1267-1270.

75. Voûte MT, Bastos Gonçalves FM, et al. Treatment of post-implantation aneurysm growth by laparoscopic sac fenestration: long-term results. Eur J Vasc Endovasc Surg. 2012;44(1):40-44.

76. Wisselink W, Cuesta MA, Berends FJ, van den Berg FG, Rauwerda JA. Retroperitoneal endoscopic ligation of lumbar and inferior mesenteric arteries as a treatment of persistent endoleak after endoluminal aortic aneurysm repair. J Vasc Surg. 2000;31(6):1240-1244.

77. Hinchliffe RJ, Singh-Ranger R, Whitaker SC, Hopkinson BR. Type II endoleak: transperitoneal sacotomy and ligation of side branch endoleaks responsible for aneurysm sac expansion. J Endovasc Ther. 2002;9(4):539-542.

78. Faccenna F, Alunno A, Castiglione A, et al. Persistent type II endoleak: two cases of successful sacotomy. Ann Vasc Surg. 2013;27(2): 240.e9-240.e11.

79. Kouvelos G, Koutsoumpelis A, Lazaris A, Matsagkas M. Late open conversion after endovascular abdominal aortic aneurysm repair. JVasc Surg. 2015;61(5):1350-1356.

80. Klonaris C, Lioudaki S, Katsargyris A, et al. Late open conversion after failed endovascular aortic aneurysm repair. J Vasc Surg 2014;59(2):291-297.

81. Böckler D, Holden A, Thompson M, et al. Multicenter Nellix EndoVascular Aneurysm Sealing system experience in aneurysm sac sealing. J Vasc Surg. 2015;62(2):290-298.

82. Brownrigg JR, de Bruin JL, Rossi L, et al. Endovascular Aneurysm Sealing for Infrarenal Abdominal Aortic Aneurysms: 30-Day Outcomes of 105 Patients in a Single Centre. Eur J Vasc Endovasc Surg. 2015;50(2):157-164.

83. de Bruin JL, Brownrigg JR, Karthikesalingam A, et al. Endovascular aneurysm sealing for the treatment of ruptured abdominal aortic aneurysms. J Endovasc Ther. 2015;22(3):283-287.
Vascular Health and Risk Management

\section{Publish your work in this journal}

Vascular Health and Risk Management is an international, peerreviewed journal of therapeutics and risk management, focusing on concise rapid reporting of clinical studies on the processes involved in the maintenance of vascular health; the monitoring, prevention and treatment of vascular disease and its sequelae; and the involvement of

\section{Dovepress}

metabolic disorders, particularly diabetes. This journal is indexed on PubMed Central and MedLine. The manuscript management system is completely online and includes a very quick and fair peer-review system, which is all easy to use. Visit http://www.dovepress.com/ testimonials.php to read real quotes from published authors. 